\title{
Energy conservation potentials of an office buildings in Northern Nigeria: a case study of Katsina secretariat complex
}

\author{
Muhammad Rabiu Abbas \\ Department of Mechanical Engineering, Hassan Usman Katsina Polytechnic, Nigeria
}

\begin{tabular}{l}
\hline \hline Article Info \\
\hline Article history: \\
Received Sep 4, 2019 \\
Revised Nov 6, 2019 \\
Accepted Nov 20, 2019 \\
\hline
\end{tabular}

\section{Keywords:}

Efficiency

Electrical energy

Energy conservation

Fossil fuel

Office buildings

\begin{abstract}
The importance of energy conservation in our contemporary world cannot be overemphasized, efficient utilization of energy has significant impact in improving economy at all levels of human endeavour. No doubt, adequate and appropriate utilization of energy especially electrical energy boosts up any organizational developmental activities. Recently, research interest has emphasis towards efficient energy utilization and energy conservation as the effective means of reducing energy consumption in buildings thereby reducing its maintenance cost. This paper investigated and analysed the energy consumption characteristics of Katsina state secretariat complex for the period of 3 years (i.e. from 2014 to 2016) based on site surveys and analysis of the energy end users present, using the records of electricity utility bills and Automotive Gas Oil (AGO), being the two energy carriers of the complex. Records have shown that, the secretariat complex average electricity and AGO annual consumptions were found as $1045661.95 \mathrm{kWh}$ and 116650.33 litres of $\mathrm{AGO}$ (which is equivalent to $1250491.54 \mathrm{kWh}$ ) respectively. The investigation revealed a distinct consumption pattern, indicating peak energy consumption during the hot months of April to August due to significant air conditioning requirements. The result of the investigation of the energy conservation potentials in the secretariat complex have shown that, energy savings of up to $6.5 \%$ of the total energy can be achieved by switching-off all security lights during the day. While turning off the air conditioners in the early morning hours of between 8am to 10am would provide a saving of up to $19 \%$ of the total energy. Furthermore, a saving of $16.5 \%$ of the total energy can be achieved when the incandescent lamps are replaced with the energy efficient ones. The energy conserving measures (ECMs) followed in this research has shown significant savings in terms of both energy and cost, and if well implemented can give way for a sustainable energy management of similar office buildings in future.
\end{abstract}

Copyright $(2020$ Institute of Advanced Engineering and Science. All rights reserved.

\section{Corresponding Author:}

Muhammad Rabiu Abbas,

Department of Mechanical Engineering,

Hassan Usman Katsina Polytechnic,

PMB 2052, Katsina, Nigeria.

Email: ibnabbas101@gmail.com

\section{INTRODUCTION}

The significance of energy conservation in modern world cannot be overstated, efficient utilization of energy has important influence in improving economy at all levels of human endeavor [1, 2]. No doubt, adequate and appropriate utilization of energy boost up any country's developmental activities [3-5]. Recently, research interest has emphasis towards efficient energy utilization and its conservation as the effective means of reducing energy consumption in buildings, thereby reducing maintenance cost [6,7]. Studies on energy evaluation conducted on buildings in hot and humid climates had identified energy conservation measures by establishing proper ways and efficient usage of electrical energy consuming devices within these buildings 
$[8,9]$. For example, an energy evaluation conducted on some hotel buildings in Qatar using these energy conservation measures have shown an energy saving between the ranges of $19.69 \%$ to $24.12 \%$ of their total energy consumption [10,11].

In addition, studies on energy conservation and cost saving measures of buildings in the Middle East region had been reported extensively in literature $[12,13]$. This led the United Arab Emirate (UAE) government for example, to implement an energy ratings system for domestic electrical appliances, air conditioning systems and lightings [10]. On the other hand, the research conducted by Bin and Dowlatabadi [14], indicated that, the United States (US) buildings consume nearly half of the country's total energy consumption through heating, cooling and power. The studies estimated that about $30 \%$ of this consumption could be saved by using energy conservation measures and/or through using sustainable building designs and operations [15]. In another research, the United Kingdom (UK) for example, consumes more than $60 \%$ of its energy for cooling/heating the indoor environment [13]. In addition, reports from some studies had found that more than $50 \%$ of all delivered energy in Europe and the United States had been associated with buildings [14, 16, 17]. However, it was shown that, the air conditioning systems were responsible for about $40 \%$ of the substantial share of the energy usage $[8,18]$. On the other hand, an extensive studies carried out on energy conservation and efficiency measures in institutions had also revealed a significant energy savings on their total energy consumptions, and as such, resulted to a huge cost savings $[19,20]$. Thus, effective energy management in an enterprise can lead to significant energy and cost savings in addition to the indirect benefits, such as extension of the equipment's service life, reduction in maintenance costs, improving comfort and environmental safety [21-23]. Hence, electrical energy in any enterprise must be efficiently managed and utilized so as to minimized losses, maintenance cost and efforts. Energy retrofits and the implementation of energy conservation measures had been found as the cost-effective means of reducing energy consumption in buildings which therefore, minimized the maintenance cost. Also, as reported in literature, changing building HVAC (Heating, Ventilation and Air Conditioning) facilities with those that have energy saving devices and adjusting their operating strategies had worked well in producing huge savings as a result of peak load reductions [15, 24, 25].

Like any other secretariat complex, Katsina state secretariat complex consumes a lot of energy daily, obviously due to the large number of buildings and facilities in the complex. Measures are generally not taken in order to conserve the energy in this environment. This is evidently in the poor maintenance culture which is one of the maladies in this nation. Usually, a lot of energy is unnecessarily wasted everyday due to negligence or ignorance. The state government can save a lot of money monthly if measures of energy conservation are taken and used effectively in the complex. These energy efficiency measures if well implemented, will help the state government redirect the utility cost savings back into the government purse for a reasonable developmental program elsewhere. Therefore, energy analysis is one of the key methods for improving energy efficiency and management in buildings [26-28]. The aim of the study is to identify and recommend efficient, less expensive and/or more environmentally friendly energy conserving measures (ECMs) for use in the Katsina state secretariat complex in order to minimized energy usage and cost.

\section{RESEARCH METHOD}

\subsection{Data Gathering}

The first stage in the investigation was collection of data, this was feasible with the cooperation of the facility manager's office in the complex and ministry of works, housing \& transport of the state. Utility bills of the secretariat complex for three years (2014 to 2016) were requested, collected and analysed. Furthermore, each section of the secretariat complex was physically examined and investigated using a walk-through data taking exercise, from which, information about the ventilation and air conditioning (VAC), electrical equipment and lightings were obtained. These data provided sufficient information on the energy consumption pattern within the secretariat complex. For example, Table 1 indicates the summary of the four major lighting types in the secretariat complex. Finally, the architectural and engineering drawings for the secretariat complex were obtained and studied information regarding the floor areas of the buildings there present. For example, Table 2 depicts the summary of the floor areas in the secretariat complex. During the investigation exercise, several ECMs were considered, based on the data obtained, energy pattern and usage, human behaviour as well as the nature of the environment in which the secretariat complex was situated. The ECMs indicated below were used for the evaluation of the energy conservation potentials in the secretariat complex. 
Table 1. Summary of the Four Major Lamp Types in the Complex

\begin{tabular}{|c|c|c|c|c|c|c|}
\hline Lamp types & Offices & Conference & Verander & Security & Corridor & Toilets \\
\hline Tabular fluorescent $(20 \& 40 \mathrm{~W})$ & $\begin{array}{c}2203 \\
95.6 \%\end{array}$ & $\begin{array}{c}52 \\
39.4 \%\end{array}$ & - & $54481.7 \%$ & $36485.6 \%$ & $\begin{array}{c}633 \\
100 \%\end{array}$ \\
\hline Compact fluorescent (40W) & $1024.4 \%$ & $\begin{array}{c}8 \\
6.1 \%\end{array}$ & - & - & $\begin{array}{c}50 \\
11.8 \%\end{array}$ & - \\
\hline Incandescent lamp/bulb (60\& 100W) & - & $\begin{array}{c}72 \\
54.6 \%\end{array}$ & $\begin{array}{c}56 \\
100 \%\end{array}$ & - & $\begin{array}{c}11 \\
2.6 \%\end{array}$ & - \\
\hline $\begin{array}{l}\text { Metal halide }(250 \mathrm{~W}) \\
\text { Total number }\end{array}$ & $\begin{array}{c}- \\
2305 \\
100 \%\end{array}$ & $\begin{array}{c}- \\
132 \\
100 \%\end{array}$ & $\begin{array}{c}- \\
56 \\
100 \%\end{array}$ & $\begin{array}{c}12218.3 \% \\
666 \\
100 \%\end{array}$ & $\begin{array}{c}- \\
425 \\
100 \%\end{array}$ & $\begin{array}{c}- \\
633 \\
100 \%\end{array}$ \\
\hline
\end{tabular}

Table 2. Summary of Floor Area in the Secretariat Complex

\begin{tabular}{lrrr}
\hline \multicolumn{1}{c}{ Ministry/Department } & \multicolumn{2}{c}{ Floor Area $\left(\mathrm{m}^{2}\right)$} & $\begin{array}{r}\text { Total Floor Area } \\
\left(\mathrm{m}^{2}\right)\end{array}$ \\
\hline S.S.G \& Lands & 1866.70 & 852.08 & 2718.78 \\
HOCSS \& Establishment & 1828.62 & 486.04 & 2314.66 \\
Min. of Finance & 1759.56 & 537.35 & 2296.91 \\
Min. of Works & 2180.33 & 791.08 & 2971.41 \\
Min. of Health & 1797.08 & 450.27 & 2247.35 \\
Min. of Information & 1341.68 & 541.78 & 1883.46 \\
Min. of Justice & 1476.61 & 554.59 & 2031.20 \\
Min. of Commerce & 964.99 & 225.16 & 1190.15 \\
Min. of Agriculture & 1626.68 & 822.48 & 2449.16 \\
Min. of Water Resources & 1056.71 & 353.91 & 1410.70 \\
Min. of Women Affairs & 1248.50 & 460.41 & 1708.91 \\
Min. of Education & 3053.70 & 1233.39 & 4287.09 \\
Mosque & 281.71 & 71.64 & 353.35 \\
Cafeteria & 505.01 & 157.68 & 662.69 \\
Conference & 698.49 & 319.91 & 1018.40 \\
\hline
\end{tabular}

\subsection{Evaluation of Energy Conservation Potentials \\ 2.2.1 No Cost Measures}

These are measures that can be implemented through behavioural and operational means without the need for system or building modifications and, therefore, do not require extra cost for its implementation [29]. For the secretariat complex, the following measures were identified for implementation.

ECM \#1: Adjusting the Set Point Temperature (SPT) in the air conditioning systems in such a way that, the cooling temperatures during the hot and cold season months are set at $21^{\circ} \mathrm{C}$ and at $24^{\circ} \mathrm{C}$ respectively as against the base case SPT of $18^{\circ} \mathrm{C}$.

ECM \#2: Switching-off of all equipment not in use and remove the ones which their life span had expired from offices.

ECM \#3: Minimizing the effect of indoor air infiltration while the air conditioning systems are in operation. It has been observed that, many times doors were left open while the air conditioning systems were under operation, this triggered large amount of energy requirements by the systems so as to cater for the proper comfort needed in the indoor environment, and directly affects the energy consumption rate by rocketing the total annual energy consumption.

ECM \#4: Scheduling of the operation of building lightings and electrical equipment is normally ignored, but its importance in any enterprise cannot be over emphasized. In this regard, the secretariat complex was no exception, it was found that the lighting and electrical equipment were left in full operation even during the low occupancy and unoccupied hours.

\subsubsection{Low Cost Measures}

These are measures which require replacing some of the building fittings or the modification of the building itself, and thus, it required extra but low cost for their implementation [30]. For the secretariat complex, the following measures were identified for implementation.

EMC \#1: Research have shown that the use of a passive cooling measure tends to reduce the thermal cooling load and also minimize heat gain from outside. This is a measure whereby the walls are protected from the direct impact of ultra-violet rays of the sun by making use of roofing running over the doors and windows or by planting trees placed at 2 meters or 3 meters away from the walls.

ECM \#2: Also, the use of energy-efficient lighting lamps and ballasts, addition of reflective devices and delamping are measures considered. 


\subsubsection{Major Investment Measures}

Replacement of $1.5 \mathrm{~kW}$ (2 hp) Air-conditioning (AC) systems with $1.13 \mathrm{~kW}$ (1.5 hp) AC systems. It is a known fact that, modern office equipment do have energy saving devices, and therefore changing the older ones with the new ones should be encouraged in the secretariat complex and similar establishments, even though this require careful scrutiny before a decision can be taken due to the substantial cost involved [11].

\section{RESULTS AND ANALYSIS}

From the result of the investigation using the recommended ECMs, the energy savings achieved in the study was encouraging. For example, from the investigation, it was found that, when the security lights were turned off during the day, a savings of up to $5.5 \%$ of the total annual energy consumption due to that sector was achieved. In addition, when a $100 \mathrm{~W}$ bulbs were replaced with $34 \mathrm{~W}$ energy efficient lamps, an energy savings of up to $15 \%$ of the total annual energy consumption from that aspect was achieved. Also, when fluorescent lamps of $40 \mathrm{~W}$ were replaced with energy efficient lamps of $15 \mathrm{~W}$, a $21 \%$ reduction in the total annual energy consumption due from that sector was achieved. Energy efficient lamps can last for 5000 to 6000 hours. Thus it indicates that, in terms of life span, power savings and even cost, the contemporary energy efficient lamps can replace the conventional fluorescent tubes. Another aspect which saves energy is the schedule of electric equipment. The investigation revealed that, when electric equipment are switch-off when not in use, an energy savings of up to $7 \%$ was achieved from the annual energy consumption of that aspect.

On the other hand, when the air conditioners were turned off during the early morning hours (between 8:00am to10:00am), a savings of up to $15 \%$ of the total annual energy consumption from that sector was achieved. Similarly, the analysis of the energy savings due to the replacement of $1.5 \mathrm{~kW}$ (2 hp) AC systems with $1.13 \mathrm{~kW}(1.5 \mathrm{hp}) \mathrm{AC}$ systems in the secretariat complex was recorded as high as $25 \%$ from the total annual energy consumption contribution from that sector during the hot season months, a time which recorded the highest usage of the $\mathrm{AC}$ systems in the secretariat complex. However, this is an energy conservation measure which require huge financial investment for its implementation. Therefore, is recommended to be implemented only through system renovation, retrofitting building's ventilation and air conditioning installations and their installations during future building constructions.

Investigations have revealed that, the secretariat complex had been run on two energy carriers, Electric energy from the national grid and AGO. However, it was revealed from the energy consumption analysis in the secretariat complex, that, the total average electric energy consumption for the period under consideration was $1045661.95 \mathrm{kWh}$ while the average energy consumption from the AGO was $1250491.54 \mathrm{kWh}$.

Table 3 shows the details of the annual electric energy consumption on monthly basis in the secretariat complex from 2014 to 2016 . From the table, it was observed that, the peak energy consumption occurred mostly between the months of March to October. This can be attributed mainly to the high energy demand to comfort indoor environment during the period stated, being the combination of two different hot seasons, for example, a hot period (i.e March to June) and hot-humid period (i.e July to October) in Nigeria. In addition, for the years under consideration, there was no clear pattern indicating any specific variation from any year to another. However, the total electricity consumption varied slightly from one year to another, due to mainly the slightly different weather conditions, and more prominently to the variation in building use and operations in the secretariat complex, especially occasional overtime work. Furthermore, Figure 1 depicts the monthly comparison of the electric energy consumption pattern in the secretariat complex for the years under appraisal. As was explained earlier, the electric energy consumption shows distinct variation, with the months from March to October indicating the highest consumption.

Table 3. Average Monthly Electric Energy Consumption in the Complex

\begin{tabular}{cccc}
\hline Month & 2014 Consumption $(\mathrm{kWh})$ & 2015 Consumption $(\mathrm{kWh})$ & 2016 Consumption $(\mathrm{kWh})$ \\
\hline January & 78739.35 & 79905.47 & 79683.35 \\
February & 75915.07 & 77088.69 & 77179.97 \\
March & 91257.32 & 91366.08 & 91295.06 \\
April & 91281.3 & 91333.36 & 91333.36 \\
May & 91416.57 & 91318.66 & 91262.66 \\
June & 90111.22 & 90370.79 & 90100.84 \\
July & 90500.57 & 90634.89 & 90562.71 \\
August & 90282.61 & 90422.81 & 90422.81 \\
September & 89695.75 & 89432.57 & 89665.84 \\
October & 90533.65 & 90004.03 & 90377.94 \\
November & 84377.9 & 84085.97 & 84321.14 \\
December & 80481.4 & 80256.47 & 79967.68 \\
\hline
\end{tabular}

Indonesian J Elec Eng \& Comp Sci, Vol. 18, No. 2, May 2020 : 629 - 635 


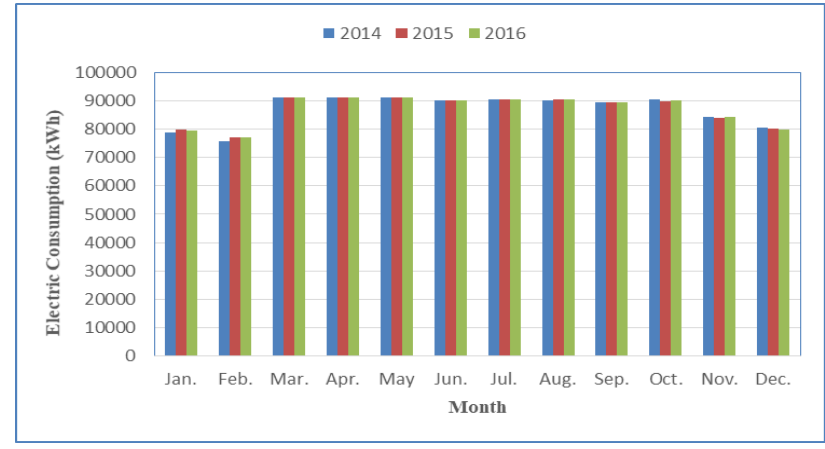

Figure 1. Average monthly electric energy consumption in the complex from 2014 to 2016

Table 4 shows the details of the annual AGO consumption in the secretariat complex by the generators on monthly basis from 2014 to 2016 and the averages. From the table, it was observed that, the peak AGO consumption occurred mostly between the months of April to August within the period under consideration. This can be attributed mainly to the high energy demand to comfort indoor environment during the period stated, being a hot session period in Nigeria. Furthermore, it can also be observed that 2014 has the highest AGO consumption, then followed by 2015 and 2016 respectively. This is an indication that, there was an improvement of electric energy supply in the secretariat complex from 2014 to 2016, and that what made the operational hours for the generating sets to reduced drastically, thereby reducing the total AGO consumption. Furthermore, Figure 2 depicts the monthly comparison of the AGO consumption pattern in the complex for the years under review. As was explained earlier, the AGO consumption shows distinct variation, with the months between April and August indicating the highest consumption. The fact that, the year 2016 recorded the lowest consumption was an indication that there was a significant improvement on the energy supply from the national grid. This supply of energy has caused the operational time of the generators to be reduced, since they are not being utilized whenever there is supply of energy from the national grid. And as such, this causes the reduction in the AGO consumption as well.

Table 4. Average Monthly AGO Consumption and Power Delivered by Generators in the Complex

\begin{tabular}{cccccc}
\hline Month & $\begin{array}{c}2014 \text { Consumption } \\
\text { (Litres) }\end{array}$ & $\begin{array}{c}\text { 2015 Consumption } \\
\text { (Litres) }\end{array}$ & $\begin{array}{c}\text { 2016 Consumption } \\
\text { (Litres) }\end{array}$ & $\begin{array}{c}\text { Average Consumption } \\
\text { (Litres) }\end{array}$ & $\begin{array}{c}\text { Average Power } \\
\text { Delivered }(\mathrm{kWh})\end{array}$ \\
\hline January & 7314.85 & 6890.7 & 5200.08 & 6468.54 & 69342.75 \\
February & 7615.09 & 7210.05 & 5430.72 & 751.95 & 72380.90 \\
March & 10434.93 & 10130.23 & 7640.04 & 9401.73 & 100786.55 \\
April & 14155.48 & 13990.46 & 10550.29 & 12898.74 & 138274.49 \\
May & 15065.20 & 14930.5 & 11260.2 & 13751.97 & 147421.12 \\
June & 14885.06 & 14740.7 & 11120.03 & 13581.93 & 145598.29 \\
July & 14615.45 & 14470.11 & 10910.22 & 13331.93 & 142918.29 \\
August & 14524.77 & 14370.08 & 10830.66 & 13241.84 & 141952.52 \\
September & 8155.52 & 7770.48 & 5860.27 & 7262.09 & 77849.60 \\
October & 7795.23 & 7390.86 & 5570.94 & 6919.01 & 74171.79 \\
November & 7364.69 & 6940.72 & 5230.86 & 6512.09 & 69809.60 \\
December & 6945.56 & 6520.08 & 4910.71 & 6125.45 & 65664.82 \\
\hline
\end{tabular}

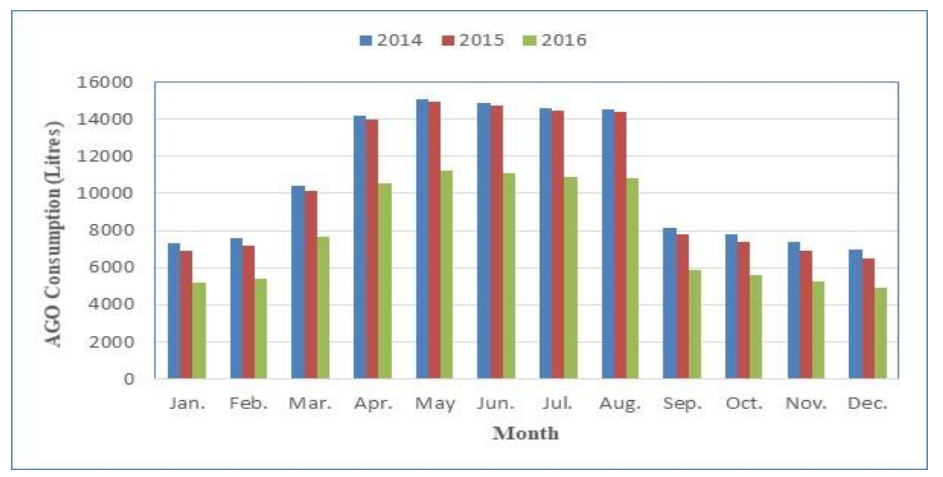

Figure 2. Average monthly AGO consumption for 2014 to 2016 


\section{CONCLUSION}

The energy conservation potentials in Katsina state secretariat complex had been investigated. It was established that up to $15 \%$ and $21 \%$ of the total energy in the consumption of the lightings system in the secretariat complex can be saved by changing the systems with the recommended energy efficient lamps of 34 Watts and 15 Watts respectively. Furthermore, a saving of $15 \%$ and $25 \%$ of the total energy consumption of the air conditioning systems can be achieved for the schedule of the systems and their replacement with lower wattage ones respectively. Hence, a significant amount of energy savings can be achieved when the prescribed energy conservation measures are implemented successfully.

\section{ACKNOWLEDGEMENTS}

The author would like to thanks the Nigerian government through the Tertiary Education Trust Fund (TetFund) program for providing the sponsorship, Hassan Usman Katsina Polytechnic and Katsina State government for giving the enabling environment for the research.

\section{REFERENCES}

[1] L. Zhao, J. Zhang, and R. Liang, " Development of energy monitoring system for large public buildings," Energy and Buildings, vol. 66, pp. 41-48, 2013.

[2] P. Shen, R. Betz, and S. K. Yong, "Energyefficiency subsdies, additionality and incentive compatibility under hidden information," Energy Efficiency, vol. 12, pp. 1429-1442, 2019.

[3] A. S. Silver, F. Luiz, A. C. Mansur, A. S. Veira, A. Schaefer, and E. Ghisi, "Knowing electricity end-uses to successfully promote energy efficiency in buildings: a case study in low-income houses in Southern Brazil," International Journal of Sustainable Energy Planning and Management vol. 2, pp. 7-18, 2014.

[4] J. Lee, J. Park, H.-J. Jung, and J. Park, "Renewable energy potential by the application of a building integrated photovoltaic and wind turbine system in global urban areas," Energies, vol. 10, p. 2158, 2017.

[5] M. R. Abbas, D. Y. Dasin, and A. S. Aliyu, "Performance of Parabolic Concentrated Solar Cooker used for Cooking Oil in Bauchi-Nigeria," Journal of Advanced Research Design vol. 3, pp. 9-22, 2014.

[6] F. E. Tang, "An Energy Consumption Study for a Malaysian University," International Journal of Environmental, Ecological, Geological and Mining Engineering, vol. 6, pp. 99-105, 2012.

[7] H. Y. T. Jeffrey and C. S. Nor Azwadi, "A Brief Review on Solar Updraft Power Plant," Journal of Advanced Review on Scientific Research, vol. 18, pp. 1-25, 2016.

[8] S. M. Hasnain, N. M. Alabbadi, and "Need for thermal storage air conditioning in Saudi Arabia," Applied Energy, vol. 65, pp. 153-164, 2000.

[9] J. Dakheel and K. T. Aoul, "Building applications, oppotunities and challenges of active shading systems: A state-ofthe-art Review," Energies, vol. 10, p. 1672, 2017.

[10] R. G. Bhavani and M. A. Khan, "Prevalence and penetration of lighting control systems in Dubai buildings: A pointer to future measures," Journal of Applied Science, vol. 8, pp. 4360-3466, 2008.

[11] S. M. Suleiman, M. R. Abbas, and A. S. Aliyu, "Investigation of Energy Conservation Potentials in Kaduna Polytechnic, Nigeria," Journal of Advanced Research in Fluid Mechanics and Thermal Sciences vol. 30, pp. 12-20, 2017.

[12] P. A. Bende and R. G. Bhavani, "Investigation of Energy Saving Potential for a University Campus in Dubai," Journal of Emerging Trend in Engineering and Applied science, vol. 6, pp. 231-235, 2015.

[13] F. Al-ajmi and V. Hanby, "Simulation of energy consumption for Kuwaiti domestic buildings," Energy Build, vol. 40, pp. 1101-1109, 2008.

[14] S. Bin and H. Dowlatabadi, "Consumer lifestyle approach to US energy use and the related CO2 emissions," Energy Policy, vol. 33, pp. 197-208, 2005.

[15] S. A. Smiai, "Effective tools toward electrical energy conservation in Saudi Arabia," Energy conversion and Management vol. 39, pp. 1337-1349, 1998.

[16] F. E. Tang, "An Energy Consumption Study for a Malaysian University," International Journal of Environmental, Ecological, Geological and Mining Engineering, vol. 6, pp. 99-105, 2012.

[17] I. Ullah, R. Ahmad, and D. Kim, "A prediction mechanism of energy consumption in resdential buildings using hidden Markov model," Energies, vol. 11, p. 358, 2018.

[18] W. Wong, L. Chen, X. Huang, L. Yang, and X. Du, "Performance recovery of natural draft dry cooling systems by combined Air leading strategies," Energies, vol. 10, p. 2166, 2017.

[19] I. Iqbal and M. S. Al-Homoud, "Parametric analysis of alternative energy measures in an office building in hot and humid climate," Building and Environment, vol. 42, pp. 2166-2177, 2007.

[20] M. S. Al-Homoud, "Optimal thermal design of office buildings.," International Journal of Energy Research, vol. 21, pp. 941-951, 1997.

[21] A. V. Pareshkumar and V. B. Purnanad, "Experimental Investigation on Energy Efficiency of Electrical Utilities in Process Industries through Standard Energy Conservation Practices," Energy Procedia, vol. 54, pp. 199-210, 2014.

[22] Y. Zhang, J. Kang, and H. Jin, "A review of green building development in China from the perspective of energy saving," Energies, vol. 11, p. 334, 2018. 
[23] S. Singh and A. Yassine, "Big data mining of energy time series for behavioral analystics and energy consumption forecasting," Energies, vol. 11, p. 452, 2018.

[24] P. K. Halder and I. Khan, " Electrical Energy Conservation through Human Behavior Change: Perspective in Bangladesh," International Journal of Renewable Energy Research vol. 6, pp. 43-52, 2016.

[25] E. H. Mathews, C. P. Botha, D. C. Arndt, and A. Malan, "HVAC control strategies to enhance comfort and minimize energy usage.," Energy and Building and Environment, vol. 33, pp. 853-863, 2001.

[26] D. N. Utazi and B. O. Ezurike, "Energy Audit of Madonna University Akpugo Campus," International Journal of Scientific Research in Information Systems Engineering, vol. 1, 2015.

[27] S. Malik and D. Kim, "Prediction-learning algorithm for efficient energy consumption in smart buildings based on particle regeneration and velocity boost in particle swarm optimization neutral networks," Energies, vol. 11, pp. 1289, 2018.

[28] S. O. Oyedepo, "Energy efficiency and conservation measurer's tools for sustainble energy development in Nigeria," International Journal of Energy Engineering, vol. 2, pp. 86-98, 2012.

[29] D. N. Utazi and B. O. Ezurike, "Energy Audit of Madonna University Akpugo Campus," International Journal of Scientific Research in Information Systems Engineering, vol. 1, 2015.

[30] S. B. Adeyemo and A. O. Odukwe, "Energy Conservation as a Viable Pathway towards Energy Stability," Journal of Engineering and Applied Sciences, vol. 3, pp. 233-238, 2008.

\section{BIOGRAPHIES OF AUTHORS}

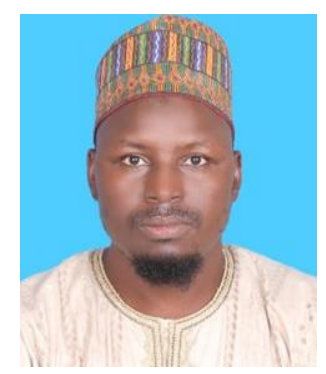

Dr. Muhammad Rabiu Abbas

A. Educational background

2016 Doctor of Philosophy (Ph.D.) Mechanical Engineering,

2010 Universiti Teknologi Malaysia (UTM), Johor Bahru, Malaysia.

2010 Master of Engineering (Energy Engineering),

1998 Bayero University, Kano, Nigeria. Bayero University, Kano, Nigeria.

B. Research interest/work

* Energy Auditing and management

* Renewable/Alternative Energy

* Automotive Turbo-machinery

* Materials Engineering

$>$ Thermal Barrier Coatings

$>$ Advanced Ceramics

$>$ Ceramic Composites

$>$ Functionally Graded Materials

$>$ Material Characterizations

* Heat and mass transfer

* Advanced Thermohydraulics

* Mechanical Structural Analysis

* Internal Combustion Engine

* Strength of Materials

* Thermodynamics Analysis

* Fluid Mechanics Analysis

C. Membership/Registration

$\checkmark$ Member, American Society of Mechanical Engineers (ASME).

$\checkmark \quad$ Registered Engineer, Council for the Regulation of Engineering in Nigeria (COREN).

$\checkmark$ Member, International Association of Advanced Materials (IAAM).

$\checkmark$ Member, Industrial Engineering and Operations Management (IEOM) Society International. 